\title{
Sponsorship of research in Public Health Nutrition
}

In this issue of the journal we have a paper by Nestle $^{1}$ that raises important ethical issues abut the way nutrition research is funded. An accompanying commentary from Vorster ${ }^{2}$ discusses these issues from the perspective of the developing world. We believe that as a journal we should encourage this debate and try to open discussion about a mode of operation that is ethically acceptable, while recognising the reality of research funding. We are not seeking to take a moral high ground that cannot be sustained and we are not opposed to industrial support of research.

Vorster $^{2}$ highlights five major perspectives from which industry sponsorship can be viewed: the position of industry, of the academic, of the professional or learned society, of journals, and of the consumer. Vorster proposes the creation of an independent nutritionfunding agency, operating like a blind trust, where money comes in from industry and is used under the guidance of a board without industry dictating or knowing which research projects are being funded. The editors would like to open discussion on this proposal. What do readers think? Are there better models to consider? Could it ever be practical?

The credibility of academic research and scholarship depends on the integrity of the people involved. We believe that money from industry, used in the right way, does not necessarily imply a threat to academic standards and rigour. In the current funding environment, researchers and learned societies must ask themselves what the costs and benefits are of accepting or rejecting industry support. Are there conditions under which it is acceptable and those under which it is not acceptable to accept industry money? The Nutrition Society, which owns this journal, accepts industry sponsorship for running its scientific meetings, but does not have sustaining members. After considerable debate, the Nutrition Society agreed that no lecture given at a society meeting would be named after a sponsor, although it is prepared to accept financial support from that sponsor. The Nutrition Society argue that the resulting benefits from the exchange of scientific information at meetings outweigh any potential harm arising from the impression that they may be 'influenced' by sponsorship from industry.
Poor research helps no one in the long term. Some consumers are sceptical about the integrity of academics, and they have a right to expect the highest moral and ethical standards. It may be naïve, but we believe that most people working in academia are honest and do have integrity. They are not in the profession for the financial rewards because most could earn far more working elsewhere. Academics choose this profession for many reasons, not least because they believe in the common good of their work.

It would of course be wrong to think that nutritionists working in academia or industry do not have personal biases, and that at times - perhaps subconsciously - they interpret their research findings to fit their prejudices. Good nutritionists are aware of this and try to operate in an evidence-based model, interacting with non-nutrition colleagues professionally and responsibly.

We believe that any potentially competing or conflicting interest should be declared, and our journal policy will be that the source and nature of the funding should be disclosed. We are not going to reject papers because they declare a potentially competing interest, but we feel the reader has a right to know the source and nature of the support used to fund the research being published. Readers can then make their own judgement.

To date we have not made any suggestions about whether reviewers should also be asked to declare any conflicts of interest. What do readers think?

In addition we propose to introduce a register of editors' interests, which will be held in the editorial office and be available to readers, along the lines currently operating for people who serve on government or public committees. Again we seek your views on this.

Barrie Margetts

Lenore Arab

\section{References}

1 Nestle M. Food company sponsorship of nutrition research and professional activities: a conflict of interest? Public Health Nutr. 2001; 4: 1015-22.

2 Vorster H. Sponsorship of nutrition research in developing countries. Public Health Nutr. 2001; 4: 1015-22. 